\title{
O cooperativismo e a função social constitucional da cooperação nas constituições da Itália e do Brasil
}

Cooperativismo y la función social constitucional de la cooperación en las constituciones de Italia y Brasil

The Cooperativism And The Constitutional Social Function Of The Cooperation In The Constitutions Of Italy And Brazil

\section{Candida Joelma Leopoldino ${ }^{1}$}

Recibido: 14 de diciembre de 2019

Aprobado: 15 de agosto de 2020

Publicado: 30 de septiembre de 2020

Cómo citar este artículo:

Leopoldino, C.J. (2020). O cooperativismo e a função social constitucional da cooperação nas constituições da Itália e do Brasil. Cooperativismo \& Desarrollo,

28(118), 1-25.

doi: https://doi.org/10.16925/2382-4220.2020.03.03

Artículo de investigación. https://doi.org/10.16925/2382-4220.2020.03.03

Doutora em Direito. Advogada e Coordenadora do Curso Técnico em Cooperativismo do Instituto Federal do Paraná - Campus Coronel Vivida, Paraná.

Correo electrónico: canjl@hotmail.com candida.leopoldino@ifpr.edu.br

ORCID: http://orcid.org/0000-0003-1937-3598 


\title{
Resumo
}

O presente estudo visa demonstrar aspectos da função social constitucional da cooperação nas constituições da Itália e do Brasil, bem como trazer alguns fundamentos da cooperação moderna, presentes nas relações humanas pela necessidade de sobrevivência. Aliada a essa ideia, apresenta-se a destacada importância da cooperação nas Constituições italiana e brasileira, em especial o incentivo ao cooperativismo nesses países. 0 trabalho foi dividido em duas partes, além da introdução e das considerações finais: a primeira parte trata especificamente da cooperação e a segunda apresenta as reflexões sobre as constituições elencandas. Verificou-se que o fenômeno da cooperação passa a assumir uma característica fundamental (ou mais especificamente um objetivo republicano fundamental), essencial e absoluta para as Constituições Federais analisadas, marcando interferência direta na ordem econômica nacional. Se antes se debatia sobre uma função social constitucional, ficou claro o papel/função da cooperação na economia, sendo que, em decorrência disso, a cooperação/cooperativismo passou a ter reconhecimento e proteção constitucional, especialmente nos países destacados neste trabalho.

Palavras-chave: Brasil, constituições, cooperação, cooperativismo, função social, Itália.

\section{Resumen}

Este estudio tiene como objetivo demostrar aspectos de la función social constitucional de la cooperación en las constituciones de Italia y Brasil, así como aportar algunos fundamentos de la cooperación moderna, presente en las relaciones humanas por la necesidad de supervivencia. Junto a esta idea, se presenta la destacada importancia de la cooperación en las Constituciones italiana y brasileña, particularmente el fomento del cooperativismo en estos países. El trabajo se dividió en dos partes, además de la introducción y las consideraciones finales: la primera parte trata específicamente de la cooperación y la segunda presenta reflexiones sobre las constituciones. Se constató que el fenómeno de la cooperación comienza a asumir una característica fundamental (o más específicamente, un objetivo republicano fundamental), esencial y absoluto para las Constituciones Federales analizadas, marcando una injerencia directa en el orden económico nacional. Si antes se debatía sobre la función social constitucional, quedó claro el rol/función de la cooperación en la economía y con ello la cooperación/cooperativismo comenzó a tener reconocimiento y protección constitucional, especialmente en los países destacados en este trabajo.

Palabras clave: Brasil, constituciones, cooperación, cooperativismo, función social, Italia.

A13 Relación de la economía con los valores sociales
P13 Empresas cooperativas
Z18 Política pública

\begin{abstract}
This study aims to demonstrate aspects of the constitutional social function of the cooperation in the constitutions of Italy and Brazil, as well as to bring some foundations of the modern cooperation, present in human relations due to the need for survival. Allied to this idea, the highlighted importance of cooperation in the Italian and Brazilian Constitutions is presented, in particular the encouragement of the cooperativism in these countries. The work was divided into two parts, in addition to the introduction and final considerations: the first part deals specifically with cooperation and the second presents reflections on the said constitutions. It was verified that the phenomenon of the cooperation starts to assume a fundamental characteristic (or more specifically, a fundamental republican objective), essential and absolute for the analyzed Federal Constitutions, marking
\end{abstract}


direct interference in the national economic order. If before there was debated about a constitutional social function, the role/function of cooperation in the economy was clear, and as a result, cooperation/cooperativism started to have constitutional recognition and protection, especially in the countries highlighted in this work.

Keywords: Brazil, Italy, Constitutions, cooperation, cooperativism, social function.

\section{Introdução}

Ao estabelecer estudos sobre os elementos fundadores do cooperativismo, em especial sobre seu desenvolvimento no cenário econômico internacional, observou-se que a sociedade cooperativa (como pensada desde o seu surgimento) e as formas das relações capital-trabalho precisavam ser analisadas e implementadas desde uma outra ótica: como necessidade fundamental de cooperação entre os interessados.

No início das relações humanas, essa cooperação era desvinculada e livre, por questões de sobrevivência e como elemento nuclear do tecido social. Com o desenvolvimento da sociedade (lato sensu), ela passou a ser funcional, com base nos termos socialmente constituídos, muitas vezes limitada pela desigualdade, hierarquia e por questões políticas e religiosas.

Assim, no século XVIII, com a Revolução Industrial, o Estado passou a controlar o avanço do capitalismo moderno, ocasião em que ocorreu um crescimento acirrado da classe proletária, sujeita ao controle e às condições de trabalho impostos pelos capitalistas. Os trabalhadores, por seu turno, passaram a se agrupar em prol da solidariedade e ajuda mútua e descobriram que, conservando a propriedade privada, sem intervenção direta do Estado na ordem econômica, seria possível obter melhores condições de vida econômica por meio da cooperação entre eles.

As primeiras iniciativas em cooperativas na Europa já demonstravam, então, que a ajuda mútua, a solidariedade e a cooperação estabeleciam-se como idealizadoras para a superação de efeitos devastadores da crise econômica, aumento de preços e diminuição de postos de trabalho. Foi exatamente isso o que ocorreu em 1844, em Rochdale, quando alguns tecelões uniram-se e criaram a primeira verdadeira cooperativa moderna de consumo, cuja finalidade era fornecer a seus integrantes as necessidades básicas a preços não onerados. Essa cooperativa buscava melhorar a precária situação econômica dos membros, com a contribuição financeira mensal de todos. Foi um caso em que a solidariedade era implementada no lugar do assistencialismo. A democracia e a autonomia passaram a servir onde antes somente existia a heteronomia e a raiz do fenômeno cooperativo na cooperação (Mauad, 2001).

No século XIX, especialmente na França, já se escrevia sobre a cooperação. Muitas vezes, tais estudos eram publicados por editoras cooperativas de propriedade 
dos operários. Na Alemanha desse período, a cooperação (por meio das cooperativas) estava ligada ao próprio movimento operário, formando uma tríade com os partidos políticos e os sindicatos, vistos como elementos de transformação social (Bragadin, 2005).

$\mathrm{Na}$ Itália, diferentemente do que ocorreu com o restante da Europa, o movimento de cooperativas já nasceu com uma multiplicidade de inspirações ideológicas e com uma cooperação reativa, como uma espécie de autodefesa. As cooperativas eram uma forma de desenvolver uma sociedade de produtores livres, buscando superar, assim, as contradições entre capital de trabalho e cooperação, um princípio geral de organização social a ser desenvolvido antes de qualquer outra iniciativa e que serviria para a emancipação dos trabalhadores.

Assim, diante do exposto e dada a sua relevância, pretende-se, com este trabalho, demonstrar aspectos do cooperativismo e da função social constitucional da cooperação nas constituições da Itália e do Brasil, importantes mecanismos de propulsão ao movimento cooperativista nesses países. A cooperação configura-se como uma vivência existente no cenário do cooperativismo mundial, diretamente ligada à sua origem como movimento social e, mais ainda, relacionada a sua importância econômica historicamente percebida.

Nesse sentido, buscando enfrentar os elementos de controle do problema e dos marcos teóricos, bem como o conjunto de conceitos e relações explorados, o trabalho foi dividido em quatro itens: a introdução; a segunda parte, que trata especificamente sobre a cooperação; a terceira, que aborda esse tema nas constituições do Brasil e da Itália e; visando concluir o trabalho, as considerações finais.

\section{Da cooperação cooperativa à teoria política da cooperação}

Pretende-se, nesta seção, apresentar uma análise mais axiológica e sociológica da própria cooperação, conceito tratado atualmente por diversas vertentes, inclusive sob o viés político internacional. Trata-se, aqui, de estudos e aprofundamentos teóricos sobre o cooperativismo, sobre o chamado espírito cooperativista e sobre sócios e sociedades cooperativas. Ao abordar estes termos, coaduna-se com Namorado (2013, p. 7), ao explicitar que eles são permeados de mistério, impossíveis de serem desvendados pela simplista descrição de fatos e eventos relacionados à sociedade cooperativa. Para o autor, "não se pode deixar de analisar o sentido do movimento cooperativo, o que implica necessariamente encará-lo como um afloramento moderno 
da cooperação, enraizado num movimento social mais amplo, o movimento operário" (Namorado, 2013, p. 7). A cooperação é, portanto, a própria raiz do fenômeno cooperativo.

A evidência histórica cooperativa iniciou-se e teve sua disseminação em um tempo relativamente recente, ao se comparar com a própria cooperação. Desde os primórdios da evolução social, por motivos de sobrevivência, os seres humanos já cooperavam. Isso acontecia ao se agruparem para suprir suas necessidades básicas, principalmente no que diz respeito à alimentação, à defesa e à perpetuação das espécies, mas também na reciprocidade de seu trabalho e no esforço conjunto de que suas ações pudessem realizar e concretizar seus propósitos e objetivos (Benato, 2002).

Eram as mais variadas formas de entreajuda voluntária, de forças e de relações de produção. A cooperação primitiva estava muito mais relacionada a um meio socialmente mais igualitário, ligados à sobrevivência e subsistência coletiva' implicando, inicialmente, na ausência de uma classe dominante. Por óbvio, com o passar do tempo, a dinâmica social fez com que a própria cooperação também passasse por um processo de hierarquização e definição de poderes ou dominações, exprimindo a emergência de desigualdade social "viabilizada e materializada pela apropriação privada sobre o produto social gerado pelo trabalho coletivo" (Namorado, 2013, p. 21).

Dada a sua importância, tem-se a cooperação como o próprio tecido aglutinador de uma sociedade e o ato de cooperar por si, o qual não é um ato novo ou específico, possui sua emergente centralidade decorrente do lugar (social ou econômico) em que é desempenhado. Então, a cooperação, que aparentemente teria somente um caráter ético ou moral, passa a demonstrar também seu papel político ao lado do mercado, subsidiando características de economicidade.

Sob o ponto de vista sociológico, a cooperação seria uma ação conjunta em que pessoas se unem para alcançar o mesmo objetivo, ou seja, uma forma de processo social de ajuda mútua para obtenção do mesmo fim. E sob esse aspecto, nas sociedades cooperativas, a cooperação passa a existir quando essa ajuda mútua é previamente organizada segundo estatutos anteriormente estabelecidos. A

1 Namorado destaca ainda que com a instituição de sociedades de exploração, a cooperação foi gradativamente se transformando em uma espécie de "colaboração forçada", ou também podendo ser classificada como uma entreajuda funcionalmente conjugada com processos coativos hierarquicamente estruturados. Em nome da sobrevivência ou subsistência, por vezes a coação era utilizada. A cooperação era gradativamente substituída pela colaboração, uma espécie de cooperação forçada. Destacada fica a diferença, neste momento, entre a cooperação, onde o êxito de cooperar se traduzia num acréscimo das oportunidades de sobrevivência de todos os cooperados, e a cooperação forçada, cujo êxito nos resultados seria um acréscimo da desvantagem relativa da grande maioria dos agentes da cooperação, em face dos proprietários dos meios de produção (2013, p. 22-24). 
cooperação, assim, dá sinais de ser uma utopia possível, bastando persegui-la como um novo paradigma, desde o início das discussões sobre economia solidária ocorridas há mais de dezesseis anos, como se verá na próxima seção.

Nesse viés, o sociólogo americano Robert A. Nisbet descreveu cinco tipos de "social interaction", sendo a cooperação a primeira e principal delas, seguida do conflito, das trocas ou das mudanças sociais, da coerção e da conformação². Para ele, "cooperation is a joint or collaborative behavior that is directed toward some goal and in which there is common interest or hope of reward"(Nisbet, 1968, p. 384).

Nessa união de esforços destacados pelo autor, a cooperação deve ser considerada como norma ética, processo social e característica estrutural de instituições não só de caráter econômico (como as sociedades), mas também de caráter religioso e político. Dentro desta classificação, o autor elenca cinco tipos de cooperação, as quais dificilmente na atualidade poderão ser encontradas de forma isolada São elas: a cooperação automática (fundamentalmente intuitiva e resultante de comportamentos não planejados); a tradicional (destacada como as normas sociais tradicionais); a contratual (relacionada com um acordo de vontade entre os participantes); a dirigida (ocorre quando a colaboração subordina-se a objetivos não estabelecidos pelos participantes) e a espontânea (a tradução natural da proximidade e cordialidade entre as pessoas) (Nisbet, 1968).

Ainda, segundo Nisbet, em um sentido amplo, toda a vida social é baseada na cooperação, já que as pessoas se reúnem em grupos e sociedades para se adaptar ao ambiente e para atender às ameaças ambientais (como inundações, fome e peste); trabalhando juntos para atender às necessidades individuais e para obter proteção contra ameaças de outras sociedades. A sociedade seria impossível sem um mínimo de esforço cooperativo. O autor destaca, ainda, que a cooperação, que tem mantido as sociedades unidas ao longo da história, pode ter se originado de uma forma espontânea, mas por meio da repetição tem se tornado costume estabelecido e tradição passada de uma geração para geração, a exemplo do que o autor chamou de cooperação tradicional.

Por outro lado, nas sociedades modernas, a cooperação tradicional passa a ser substituída por uma cooperação dirigida por um terceiro que detém uma posição de autoridade, um empregador, um professor, por exemplo. É o que Nisbet chamou de cooperação contratual, quando os grupos ou indivíduos concordam em cooperar em determinadas maneiras explícitas. A cooperação, assim, não serve para tentar escamotear a realidade posta, mas sim para mantê-la.

2 Tradução livre para "1. Cooperation 2. Conflict 3. Social Exchange 4. Coercion 5. Conformity." 
Em patamares mais amplos, Torres e Torres (1983), por sua vez, falavam sobre a existência de uma ciência da cooperação, sendo fática, normativa, humana e bidimensional, cujo objeto essencial de estudo seria a cooperativa, daí porque chamada de Cooperação cooperativa. Considera-se que essa ciência é fática porque tem como fontes os fatos; é considerada normativa e humana uma vez que visa a guiar uma conduta humana para uma finalidade relacionada à justiça social e é, por fım, bidimensional, pois interliga a facticidade à normatividade.

Assim, a cooperação cooperativa traduziria o movimento cooperativo contemporâneo, pois possui como elemento centralizador uma ação cooperativa, voluntária, realizada por, no mínimo, duas pessoas com direitos iguais e na busca dos mesmos benefícios, diversos do lucro, o qual mais tarde foi chamado de ato cooperativo. 0 autor destaca que, somente com o próprio esforço científico de estudo objetivo de como funciona a cooperação, poderia ser possível a compreensão da ciência e do todo o fenômeno cooperativo tal como se manifesta: "a cooperativa, o ato cooperativo, o sector cooperativo e a ideologia" (Torres e Torres Lara, 1983, p. 47).

Assim, quando essa ciência presenciar o conhecimento da realidade, seria possível o desenvolvimento de melhores técnicas e mecanismos de aperfeiçoamento das cooperativas e do cooperativismo em si. Para Blanco, "el fracaso de muchos programas cooperativos se ha producido por aplicar sin adaptación técnicas de empresa privada o pública. Hay que partir de conocer el objeto [...] la cooperación"3

Uma ciência da cooperação pretende, segundo Torres e Torres Lara, estabelecer certos princípios explicativos de comportamentos cooperados. O problema é que, dada a própria juventude do termo, os estudiosos seguem tratando o cooperativismo como uma ideologia 4 , somente recentemente tendo iniciado estudos universitários sobre essa ciência. Assim, tem-se que a preocupação doutrinária sobre a ciência da cooperação é recente, uma vez que, no início do século passado, autores como Totomianz e Ramirez já demonstravam preocupação ao assunto referindo-se à moderna ciência cooperativa, a qual ocupava-se não somente com o bem-estar dos indivíduos, mas também com o bem-estar de seus aglomerados.

3 BLANCO, 1990, p. 73 citado em TORRES Y TORRES LARA (1983).

4 "Para Torres el problema radica en que por la gran carga ideológica que tiene el Cooperativismo, pués nació como reacción ante el modelo capitalista de producción, los más importantes tratadistas han orientado sus estudios en esta dirección dejando de lado el análisis del fenómeno cooperativo. Frente a este critica la posición inversa, sustentada para él sobre todo por la escuela alemana que pretende estudiar la Cooperación científicamente a partir de la forma en como operan las cooperativas. Pretenden obtener princípios explicativos con la observación del comportamiento eficiente o ineficiente de las organizaciones, con total olvido de la doctrina" (BLANCO, 1990, p. 73). 

do Brasil

Tempos depois, Namorado relata a realização de Congressos de Ciências Cooperativas e a criação, em 1981, do CIUDEC (Centro de Apoyo a las Investigaciones Universitarias en Ciencias de la Cooperación), oportunidade em que um " grupo de universitários europeus e americanos apelou ao esforço das Universidades para o desenvolvimento desta ciência" (Totomianz, 1938; Ramirez, 1989), reforçando a ideia de que de fato existe uma ciência da cooperação.

Ao tratar da cooperação, incluindo-a como uma nova ciência, Ramirez a destaca como sendo um elemento das formas associativas existentes em todos os grupos humanos, assim, um fato real e passível de conhecimento. Ocorre que essas formas de associação, especialmente as cooperativas, sempre foram somente objeto de estudos minimalistas em outras ciências, como ocorre no direito, na economia, administração de empresas ou sociologia, a partir da ótica destas ciências e de forma vertical. De acordo com o autor, "Isso teve como consequência que a cooperação tratada desta forma, sem conservar uma unidade conceitual, estilhaçou-se em múltiplas perspectivas que Ihe fizeram perder a sua unidade como entidade" (Ramirez, 1989, p. 69).

Outrossim, muito embora o termo cooperação cooperativa possa parecer um mero pleonasmo, uma repetição despropositada, percorrendo o raciocínio de Ramirez, percebe-se o contrário. Parte-se de um conceito amplo de cooperação, em que é possível "qualquer coordenação de ações de vários indivíduos para realizarem uma determinada atividade", para um aspecto mais limitado em que pessoas se unem para a realização de objetivos comuns e específicos, objetivos que podem variar das mais diversas espécies tais como econômicos, sociais, culturais e até mesmo religiosos (Totomianz, 1938, p. 69).

Como fundamento teórico, tem-se que a cooperação cooperativa, assim, é a manifestação do limiar, do aspecto econômico da cooperação, caracterizada pela "[...] economicidade dos sujeitos que nela intervém, das atividades que a materializam e dos objetivos comuns, cujos benefícios valem pelo que representam para os próprios intervenientes", como pessoas e não como detentores de capital. Esse grupo organizado pode ser caracterizado de diversas formas, sendo a sociedade cooperativa, inicial e historicamente, seu paradigma mais marcante, podendo, por seu turno, também ser caracterizado por outras formas de organização semelhante, como ocorre com as associações de terceiro setor, mas também nas redes de cooperação e de economia solidária e nas diversas novas formas de economia.

Por outro lado, ocorre que todo esse conjunto de conceitos ideais de cooperação e da própria existência de uma ciência da cooperação demonstrou a existência de problemas e lacunas na sua idealização. Inicialmente, ressalta-se novamente que, 
além de características éticas e morais, a cooperação deve ter também um projeto, um papel político e econômico. Tendo isso em vista, o italiano Stefano Zamagni (2002), além de levantar o questionamento, passa a antecipar a proposição de soluções para eventuais problemas de uma teoria da cooperação.

Segundo o autor, em primeiro lugar, cada um dos participantes na ação conjunta/coletiva se assume como significativo e, portanto, digno de respeito de forma mútua, condição chamada de receptividade mútua (mutual responsiveness), a qual não é suficiente para que os sócios/envolvidos queiram realizar a mesma ação; eles devem querer fazê-la juntos. Em segundo lugar, todos se envolvem e se comprometem em uma atividade conjunta - ainda que por razões e em intensidades diferentes - e sabem que os outros pretendem fazer o mesmo. Por fim, todos têm o compromisso de ajudar os outros em seus esforços para que o resultado final possa ser melhor alcançado (commitment to mutual support), sendo, como resultado, praticamente impossível quantificar a contribuição específica de cada um para o conjunto de produtos.

Nota-se que a ajuda mútua é para ser revelada ao desenrolar da atividade conjunta e não lateralmente ou no final da ação. Esse compromisso não deve ser confundido com atitude de interesse próprio nem com altruísmo desinteressado. Sendo uma conexão de interesses, é na prestação de ajuda aos outros que o indivíduo continua a perseguir seus próprios interesses. Em outras palavras, o sócio-cooperador, por causa da preocupação com seu bem-estar, está preocupado também com o bem-estar dos outros sócios. Essa é a interpretação específica do princípio de reciprocidade em que atua a sociedade cooperativa ${ }^{5}$.

Assim, para que uma cooperativa atenda a essas condições, por um lado, deve tornar acessivel a comunicação entre os sócios/interessados, adaptando a forma das decisões e deliberações; por outro lado, deve esforçar-se para praticar a justiça, evitando qualquer subjugação ou exploração (Viola, 2004). De acordo com Joshua Cohen (1989), a cooperação é baseada na "deliberazione focalizzata sul bene comune in cui chi vi partecipa si dichiara disponibile a mettere in gioco le proprie preferenze iniziali, perché le preferenze e le convinzioni rilevanti sono quelle che emergono da o sono confermate per mezzo della deliberazione" ( p. 69).

Nesse sentido, a cooperativa pode ser vista como uma organização orientada para uma missão que vai buscar a sua força a partir das motivações intrínsecas dos agentes. $\mathrm{O}$ agente que persegue um determinado fim motiva-se porque ele sabe que há um benefício intrínseco em concluir determinado ato ou se comportar de uma certa maneira.

\section{Para aprofundar ver Zamagni 2002, p. 67.}


Por fim, como dito no início do desenvolvimento desse item, a teoria da cooperação adquire um viés também político, conhecido como a teoria política da cooperação, defendida pelo italiano Michele Filippini (2014). O autor, ao realizar tal proposição, inicia a discussão demonstrando a real possibilidade e necessidade dessa teoria. Segundo ele, na história das interpretações do fenômeno da cooperação dois caminhos específicos agiram predominantemente.

O primeiro destinou-se à pesquisa e à consolidação de uma teoria econômica de cooperação, ou seja, para mostrar como seus benefícios sociais também poderiam produzir benefícios econômicos, seja em nível micro ou macroeconômico.

O segundo caminho, em vez disso, virou-se para a organização prática das cooperativas, identificando cada modelo de negócio e suas características específicas. Ou seja, como um modelo de cooperação é mais benéfico não tanto e não apenas do ponto de vista econômico, mas também para a eficaz cooperação dos seus sócios. $\mathrm{E}$ é justamente no cruzamento dessas duas linhas que surge a possibilidade de identificar uma teoria política de cooperação.

Uma teoria política de cooperação deve buscar união com essas deseconomias $^{6}$, sendo capaz de lidar de forma diferente com os desafios colocados pela crise contemporânea. Assim, percebe-se como essas deseconomias, em face a regras econômicas que as criaram, na realidade, são combustível para o cooperativismo, criando elementos de segurança que permitem uma melhor produção e estabilidade de bens e serviços, assim como renda individual.

No campo de estudos econômicos, uma primeira resposta é dada para o problema de uma eventual marginalização da cooperativa (Salani, 2008; Salani, 2006; Zuppiroli, 2006). Não tem sido limitado, nesse esforço, enfatizar a eficiência econômica das cooperativas. Mas esse campo foi mais longe, questionando os mesmos critérios de avaliação para a eficiência no mercado, enfatizando a distinção entre economia de mercado e da economia capitalista (Braudel, 2006), em que a primeira seria um conjunto maior que contém, sem esgotar, a segunda.

Ao mesmo tempo, se a teoria econômica tem considerado, muitas vezes, a cooperação em oposição à racionalidade individual do interesse próprio, outros estudos recentes têm a colocado no centro de uma racionalidade que é individual, mas que melhora os aspectos da cooperação, o raciocínio em modelos diferentes em comparação com a da escolha racional feita com base do lucro individual (Bruni, 2006). A motivação que determina a ação daqueles que se movem dentro de relação de grupo

6 Uma deseconomia ocorre quando há um efeito inverso à geração de ganhos, ou seja, há o aumento nos fatores de produção (custos em geral como matéria prima, transporte, imperfeições no mercado), mas o resultado é um aumento menor (menos lucro) no produto ou resultado final. 
não é essencialmente instrumental: explica-se, em vez de uma lógica que dá lugar ao sentimento de pertença, o desejo de seguir as normas sociais, a dever, confiança ou reciprocidade.

Além da medição correta da eficiência das cooperativas - tarefa de uma teoria econômica da cooperação -, existe também a possibilidade de outro tipo de medida, o da eficiência social de um sistema caracterizado pela cooperação, como a interação privilegiada.

Assim, uma mudança necessária, nos campos teórico e de análise, é passar a ter consciência de que a cooperativa nasce como uma resposta à incapacidade das empresas para fornecer respostas a algumas necessidades sociais específicas. E de que possui também um papel residual na utilização da liberalidade das pessoas para fazer valer sua liberdade no controle sobre o seu trabalho, de participar na autorealização da própria personalidade, contribuindo socialmente para a criação de bens de consumo (Zamagni, 2006). A teoria econômica, que viu a firma individual como o ponto de partida de construções teóricas e o ponto de recaída de todas as intervenções possíveis, parece cada vez mais contrariada pela visão típica do mundo cooperativo.

Ainda, segundo Filippini (2014), a segunda aquisição de uma teoria política de cooperação pode, portanto, ser uma possível mudança do núcleo teórico de análise. A erosão do capital social, por exemplo, não tem, nesse contexto, o resultado da tomada de organização da produção ineficiente, mas uma distribuição irracional dos recursos, na maior parte das vezes desiguais e não funcionais para a produção social. Assim, a longa história do conceito de cooperação auxilia, em seguida, a encontrar um terceiro elemento.

Cooperação significa, sobretudo, specializzazione e divisione, non omologazione, concordância nas diferentes funções. A cooperação não se situa, em seguida, no léxico da economia clássica, o polo oposto do interesse individual, mas como fundamento último deste mesmo interesse. Ela está presente, juntamente com a solidariedade, a democracia e a reciprocidade, em práticas econômicas e sociais bem atuais, e quase que, em sua maioria, ausentes qualquer normatividade formal e adequada sobre o tema. Pode-se interpretar a relação entre cooperação e interesse individual, historicamente, bem como logicamente, como uma proporção de uma instituição em confronto com a outra (Filippini, 2014). É a consciência coletiva sobre o individualismo.

O mundo da cooperação, assim, com seu conjunto de sentidos (moral, político e econômico), com um projeto de democratização das esferas, pode dar um notável contributo à superação de antinomias aparentemente irredutíveis, tornando-o assim 
um fator de crescimento, ocasionado pela construção de uma boa sociedade para se viver.

Nesse sentido, perpassado o caminho da cooperação, a próxima seção buscará abordar como ela está descrita e fundamentada nas Constituições do Brasil e Itália.

\section{Aspectos Constitucionais da Cooperação: Função Social da Cooperação nas Constituições da Itália (1948) e do Brasil (1988)}

Para uma compreensão de princípios constitucionais que guiaram os intérpretes constitucionais, é mister que seu estudo inicie a partir da verificação de problemas e da realidade econômica contemporânea, coadunando-se com uma série de avaliações preliminares sobre o projeto que as Constituições brasileira (Constituição Federal de 1988) e italiana (Constituição Italiana de 1948) buscaram promover.

A verdade é que é difícil ignorar a realidade que esses projetos continham em seus princípios fundamentais, em que o foco na pessoa humana é consumido em conflitos (especialmente no caso italiano), na explosão do nacionalismo, nas atitudes de protecionismo econômico e social contra os mais fracos, na propagação do fenômeno da chamada nova pobreza (Bagnoli, 2011, p. 12), termo muito utilizado especialmente na Europa.

Ao iniciar pela Constituição italiana, muito semelhante à brasileira (ou essa semelhante àquela, já que quarenta anos mais recente), parece inegável que o documento italiano transpira uma concepção da vida social em suas diversas formas e explicações, que vê seu centro na pessoa humana como fundação de foco individual e coletivo de uma série de direitos não existentes nas fórmulas codificadas, mas ligado ao desenrolar da vida cotidiana (Bagnoli, 2011).

Essa concepção da vida social é arte explícita consagrada no artigo $2^{\circ}$ da Constituição italiana $(\mathrm{CI})^{8}$, regra que confirma a estreita correlação entre o gozo de direitos, definido como inviolável, e o cumprimento de deveres, qualificado como obrigatório, econômico e social. Esta correlação é reafirmada, entre outras coisas, pelo

7 E por Nova pobreza: L'espressione "nuove povertà" gode oggi di un'ampia diffusione. La crisi economica, la disoccupazione, la precarizzazione delle situazioni di lavoro e la contrazione dei consumi, hanno esposto, infatti, sempre più individui ad una condizione di vulnerabilità e povertà (Bagnoli, 2011, p. 12).

8 Art. 2. La Repubblica riconosce e garantisce i diritti inviolabili dell'uomo, sia come singolo sia nelle formazioni sociali ove si svolge la sua personalità, e richiede l'adempimento dei doveri inderogabili di solidarietà politica, economica e sociale. 
art. $4^{9}$, no qual é combinado o reconhecimento do direito ao trabalho com um dever a cumprir de acordo com sua capacidade e escolha individual, atividade que contribui para o progresso material e espiritual da sociedade.

$\mathrm{O}$ art. $3^{10}$, também da $\mathrm{Cl}$, reafirma a dignidade social de cada pessoa humana, prenunciando uma sociedade na qual a estrutura social e institucional é marcada por valores personalistas e não economicistas, pela subordinação da lógica econômica à humanização social e pela participação efetiva dos trabalhadores na vida associada, política, econômica e social, em todas as suas formas. Tanto é assim que a República, ou seja, a comunidade de cidadãos em todas as suas expressões, está empenhada em reestruturar as cooperativas, de modo a eliminar com precisão os obstáculos econômicos e sociais.

Embora muito semelhante à Constituição brasileira até o momento, destaca-se que a Constituição italiana, em seu art. 4511, expressamente reconheceu o instituto da função social da cooperação, sem, no entanto, fornecer uma definição explícita. Naquele país, a regra estabelece: "A República reconhece a função social da cooperação de natureza mutualista e sem fins de exploração privada" (Sentenza 408, 1989).

Além disso, a Assembleia Constituinte, na elaboração e discussão do artigo 45, passou sem dificuldade pela primeira parte do primeiro parágrafo. No entanto, permaneceu por um longo tempo na segunda parte, que trata da regulamentação dos controles sobre o caráter e o propósito das várias cooperativas. Com esse trabalho, o legislador constituinte implicitamente delegou à lei ordinária a tarefa de fornecer e garantir a conformidade do fenômeno cooperativo de paradigma geral da função social, além da ausência de efeitos da especulação privada, por meio do instrumento de controle (Bagnoli, 2011; e Di Marco (2013); de Pascale, 2013).

9 Art. 4. La Repubblica riconosce a tutti i cittadini il diritto al lavoro e promuove le condizioni che rendano effettivo questo diritto. Ogni cittadino ha il dovere di svolgere, secondo le proprie possibilità e la propria scelta, un'attività o una funzione che concorra al progresso materiale o spirituale della società.

10 Art. 3. Tutti i cittadini hanno pari dignità sociale e sono eguali davanti alla legge, senza distinzione di sesso, di razza, di lingua, di religione, di opinioni politiche, di condizioni personali e sociali. È compito della Repubblica rimuovere gli ostacoli di ordine economico e sociale, che, limitando di fatto la libertà e l'eguaglianza dei cittadini, impediscono il pieno sviluppo della persona umana e l'effettiva partecipazione di tutti i lavoratori all'organizzazione politica, economica e sociale del Paese.

11 Art. 45. La Repubblica riconosce la funzione sociale della cooperazione a carattere di mutualità e senza fini di speculazione privata. La legge ne promuove e favorisce l'incremento con i mezzi più idonei e ne assicura, con gli opportuni controlli, il carattere e le finalità. La legge provvede alla tutela e allo sviluppo dell'artigianato. 
E essa função social constitucional da cooperação é de fato tão presente na vida italiana que a própria Corte Constitucional Italiana, em vários dos seus acórdãos ${ }^{12}$, sublinha essa lógica, notando, em primeiro lugar, que "I'obiettivo della promozione della cooperazione come strumento di democrazia economica e di sviluppo sociale". Assim, busca garantir que a proteção constitucional da cooperação seja justificada pelas mais estreitas ligações da função social presentes nas organizações cooperativas com relação às outras formas de organização produtiva e, em particular, na realização conjunta de descentralização democrática do poder, na organização e gestão de produção e na distribuição mais ampla e mais equitativa do resultado útil da produção.

Por outro lado, há dúvida se a normativa do art. 45, parágrafo $1^{\circ}$, da $\mathrm{Cl}$ - que contém uma noção unitária ou pluralista de cooperação - permanece. Em outras palavras, o referido texto constitucional não deixa claro se ele pede aceitação de um modelo de cooperação na forma típica, ou deixa espaço para formas atípicas, passíveis de recurso ao nível constitucional.

Para tentar desenhar, pelo menos, o esboço de avaliação constitucional da matéria exposta, é mister também a análise dos arts. 2 e $18^{13}$ do mesmo diploma, em que o primeiro reconhece a dignidade de grupos sociais como um lugar de explicação da personalidade humana e o segundo pontua o reconhecimento fundamental de formações sociais, típica da liberdade, sendo as únicas limitações as contidas no direito penal.

Além disso, o fenômeno cooperativo está contemplado dentro da chamada constituição econômica, isto é, no Título III da Parte I do texto constitucional, conjugando-se, como outras atividades econômicas, com a função social que o interesse prosseguido deve garantir. Nessa perspectiva, uma simples associação sem fins lucrativos provavelmente não poderia ser atribuída à categoria existente no art. 45 da Cl, a menos que se destinasse a exercer uma atividade econômica. Basta pensar, para ver a limitação desse pressuposto, na grande variedade de associações voluntárias e

12 Sentenza 408/1989. GIUDIZIO DI LEGITTIMITÀ COSTITUZIONALE IN VIA INCIDENTALE. Presidente SAJA - Redattore. Camera di Consiglio del 12/04/1989 Decisione del 06/07/1989. Deposito del 18/07/1989 Pubblicazione in G. U. 26/07/1989 n. 29. e Sentenza 372/2004. GIUDIZIO DI LEGITTIMITÀ COSTITUZIONALE IN VIA PRINCIPALE. Presidente ONIDA - Redattore CAPOTOSTI. Udienza Pubblica del 16/11/2004. Decisione del 29/11/2004. Deposito del 02/12/2004 Pubblicazione in G. U. 09/12/2004 n. 0. Disponíveis em: http://www.cortecostituzionale.it/actionPronuncia.do.

13 Art. 18. I cittadini hanno diritto di associarsi liberamente, senza autorizzazione, per fini che non sono vietati ai singoli dalla legge penale. Sono proibite le associazioni segrete e quelle che perseguono, anche indirettamente, scopi politici mediante organizzazioni di carattere militare. 
cooperativas, fenômeno novo no mundo das formações sociais, mas que certamente não é estranho aos princípios e liberdades consagrados na Cl (Bagnoli, 2011).

Uma outra consideração pode ser feita para salientar que a terminologia utilizada na Cl tem um estilo técnico e jurídico bem defınido, já que a própria Constituição é responsável por promover a coordenação das atividades econômicas privadas para fins sociais. Ao mesmo tempo, o texto do art. $46^{14}$ identifica uma reserva específica de lei para a regulamentação do direito dos trabalhadores de colaborar na gestão das empresas. Seria difícil perder, nessas chamadas, uma distinção implícita entre iniciativa econômica privada - a ser coordenada em suas expressões individuais até a institucionalização de cogestão - e a atividade particular, que faz da mutualidade sua própria razão de ser.

Num cenário diverso do que ocorreu com o pós-guerra da elaboração da Constituição Federal Italiana, com a característica de ter se iniciado com o término de um período de ditadura militar, em $1^{\circ}$ de fevereiro de 1987, sob a presidência do então Presidente do Supremo Tribunal Federal, Ministro José Carlos Moreira Alves, foi instalada a Assembleia Nacional Constituinte no Brasil. Esta Assembleia foi formada por vinte e quatro subcomissões, as quais foram incumbidas de dar início à elaboração da futura Constituição Federal brasileira (CF). Desde o início dos trabalhos, segundo Cunha (1990), verificou-se a impossibilidade da realização de trabalho constitucional enxuto, incisivo e objetivo, até porque, como se verá a seguir, inclusive no que tange ao próprio cooperativismo, inúmeros dispositivos ficaram dependendo de leis complementares e ordinárias, fazendo com que o novo texto constitucional ficasse sem imediata aplicação.

Após inúmeras emendas e alguns projetos substitutivos, em 05 de outubro de 1988, a Constituição da República Federativa do Brasil foi promulgada ${ }^{15}$. E, especificamente no que tange ao cooperativismo, a CF marcou o início de uma nova fase, a da liberalização, em que coube ao Estado o apoio ao desenvolvimento do cooperativismo, isentando as sociedades da autorização prévia, dispondo sobre o adequado tratamento tributário ao ato cooperativo, às cooperativas de garimpeiros e às cooperativas de crédito.

14 Art. 46. Ai fini della elevazione economica e sociale del lavoro in armonia con le esigenze della produzione, la Repubblica riconosce il diritto dei lavoratori a collaborare, nei modi e nei limiti stabiliti dalle leggi, alla gestione delle aziende.

15 A Constituição foi aprovada por meio de voto eletrônico de 474 votos a favor, 15 contra e 6 abstenções. Somente a título de curiosidade, o então deputado Luiz Inácio Lula da Silva foi o líder dos que votaram contrariamente ao texto, posteriormente justificando que sua bancada assim o fez porque não estava satisfeita com o resultado do trabalho da Constituinte em razão de ela ter deixado de analisar algumas reivindicações de seu partido (CUNHA, 2010, p. 120). 
Assim, tem-se que, de forma muita enxuta, assemelhando-se ao que ocorreu no texto italiano, a partir de 1988, as sociedades cooperativas gozam de plena liberdade no aspecto legislativo, bem como no que concerne ao seu regime jurídico ${ }^{16}$. Nesse sentido, uma característica constante no XVIII do art. $5^{\circ}$ (rol dos direitos e garantias fundamentais) mostra-se como um dos mais importantes elementos dispostos no texto da CF/88, vedando toda e qualquer forma de ingerência do Estado na organização das cooperativas, as quais podem existir independentemente de autorização prévia.

O cooperativismo, nesse momento, passa a ser considerado cláusula pétrea, modificável somente por rigoroso processo de emenda constitucional17, o que demonstra, inclusive, o amadurecimento de toda a sociedade brasileira. Para Rossi, "o cooperativismo passa a fazer parte das diretrizes fundamentais que organizam e orientam o Estado, e dos princípios e valores que, ao se positivarem na Constituição, refletem a ideia de direito subjacente à sociedade" (2005, p. 129).

16 Art. 5. Todos são iguais perante a lei, sem distinção de qualquer natureza, garantindo-se aos brasileiros e aos estrangeiros residentes no País a inviolabilidade do direito à vida, à liberdade, à igualdade, à segurança e à propriedade, nos termos seguintes:

XVIII - a criação de associações e, na forma da lei, a de cooperativas independem de autorização, sendo vedada a interferência estatal em seu funcionamento;

Art. 146. Cabe à lei complementar:

III - estabelecer normas gerais em matéria de legislação tributária, especialmente sobre:

c) adequado tratamento tributário ao ato cooperativo praticado pelas sociedades cooperativas

Art. 192. 0 sistema financeiro nacional, estruturado de forma a promover o desenvolvimento equilibrado do País e a servir aos interesses da coletividade, em todas as partes que o compõem, abrangendo as cooperativas de crédito, será regulado por leis complementares que disporão, inclusive, sobre a participação do capital estrangeiro nas instituições que o integram.

17 Art. 60. A Constituição poderá ser emendada mediante proposta:

I - de um terço, no mínimo, dos membros da Câmara dos Deputados ou do Senado Federal;

II - do Presidente da República;

III - de mais da metade das Assembléias Legislativas das unidades da Federação, manifestando-se, cada uma delas, pela maioria relativa de seus membros.

$\S 1^{\circ} \mathrm{A}$ Constituição não poderá ser emendada na vigência de intervenção federal, de estado de defesa ou de estado de sítio.

$\S 2^{\circ} \mathrm{A}$ proposta será discutida e votada em cada Casa do Congresso Nacional, em dois turnos, considerando-se aprovada se obtiver, em ambos, três quintos dos votos dos respectivos membros.

$\S 3^{\circ} \mathrm{A}$ emenda à Constituição será promulgada pelas Mesas da Câmara dos Deputados e do Senado Federal, com o respectivo número de ordem.

$\S 4^{\circ}$ Não será objeto de deliberação a proposta de emenda tendente a abolir: IV - os direitos e garantias individuais. 
Ademais, é imprescindivel ressaltar nesse momento que a CF instituiu, em seu artigo $3^{\circ}$, como um de seus princípios fundamentais a construção de uma sociedade livre, justa e solidária, de modo que, assim determinando, desde o início, incluiu o cooperativismo como um dos instrumentos possíveis para a construção dessa sociedade, já que a solidariedade é a sua própria essência e intenção. Outrossim, com relação à função social da cooperação no caso constitucional brasileiro, o termo não foi utilizado de forma expressa, mas implicitamente. Juntamente com a função social da propriedade, o estímulo e o incentivo ao cooperativismo também constam no Título VII, da chamada Ordem Econômica e Financeira, especificamente no que tange aos "Princípios gerais da atividade econômica". Meinen (2002) destaca que o parágrafo $2^{\circ}$ do artigo $174^{18}$ é o mais abrangente e significativo de todos os postulados constitucionais que prestigiam o cooperativismo, ao afirmar que a lei apoiará e estimulará o cooperativismo, em todos os aspectos constantes e descritos na Constituição Federal. Assim, o direito de associar-se, com vista à defesa de interesses comuns, pode ser vislumbrado nas mais variadas formas, encontrando no "cooperativismo, em qualquer de seus ramos, umas das mais autênticas possibilidades de concretização" (Meinen; Domingues; Domingues, 2002, p. 25).

Não é difícil imaginar que, como tal, um quadro de valores constitucionais não poderia deixar de traduzir bem um setor cada vez mais estratégico da economia. Além disso, nessa frente, é a Constituição o texto capaz de fornecer os critérios de orientação e compreensão da nova realidade.

Os legisladores constituintes, especialmente os italianos, então, parecem traçar um esboço de definição que se refere a uma disciplina do fenômeno que já existe, o que, no novo contexto constitucional, é necessário para garantir a função social. Ao mesmo tempo, no entanto, esse adiamento conceitual demonstra que os textos constitucionais não conseguem distinguir com clareza suficiente os tipos de atividades de cooperação que possam ser abrangidos pela disposição da norma. É necessário recordar, de fato, que nem o Código Civil ou as leis especiais contêm uma definição da cooperação.

18 Art. 174 - Como agente normativo e regulador da atividade econômica, o Estado exercerá, na forma da lei, as funções de fiscalização, incentivo e planejamento, sendo este determinante para o setor público e indicativo para o setor privado.

$\S 2^{\circ} \mathrm{A}$ lei apoiará e estimulará o cooperativismo e outras formas de associativismo;

$\S 3^{\circ} \mathrm{O}$ Estado fornecerá a organização da atividade garimpeira em cooperativas, levando em conta a proteção do meio ambiente e a promoção econômico-social dos garimpeiros;

$\S 4^{\circ}$ As cooperativas a que se refere o parágrafo anterior terão prioridade na autorização ou concessão para pesquisa e lavra dos recursos e jazidas de minerais garimpáveis nas áreas onde estejam atuando, e naquelas fixadas de acordo com o art. 21, XXV, na forma da lei. 

do Brasil

Na Itália, o artigo 2511 do Código Civil distingue a sociedade cooperativa pelo seu objetivo comum e não lucrativo, ou seja, como contido no Relatório ao Código Civil n 1023, com a finalidade predominantemente mutualística. Na Itália, a legislação especial em nada acrescenta à necessária definição legal.

No Brasil, com o advento da Lei das Cooperativas, Lei nº 5.764/19719 ${ }^{19}$, vigente até hoje, foi iniciado um processo de renovação das estruturas do cooperativismo, momento em que houve a mitigação da presença e intervenção estatal no setor.

A Lei n 10.406, de 10 de janeiro de 2002, o atual Código Civil Brasileiro (CC), por seu turno, por ser um marco legal do direito privado nacional, tratou em um capítulo específico sobre as sociedades cooperativas. No entanto, não abordou a cooperação ou o cooperativismo em si, limitando-se a reproduzir os princípios a serem aplicados a esse tipo societário, não trazendo à discussão grandes novidades sobre o assunto. O texto civil $^{20}$ poderia ter representado um instrumento de renovação e atualização das sociedades cooperativas e, apesar disso, modificou algumas poucas questões. Acabou, assim, em um texto contraditório e pouco significativo de modificações e inovações para o tema. Ao esculpir o texto do Código Civil, o legislador, nas palavras de Krueger (2002, p. 109), optou "claramente por contemplar apenas soluções jurídicas sedimentadas e estáveis, evitando, no que tange às cooperativas, questões cujo debate resta aberto na sociedade".

Uma das soluções dadas pelo CC diz respeito à natureza jurídica da sociedade cooperativa. $O$ artigo $4^{\circ}$ da Lei $n^{\circ} 5.764 / 71$ declara que as cooperativas têm forma e natureza jurídicas próprias e, em seguida, assevera que a sua natureza é civil, causando certa contradição sobre qual seria realmente sua natureza jurídica. O CC, por seu turno, no artigo 982²1, parágrafo único, estabeleceu que, independentemente de seu objeto, a sociedade cooperativa terá sempre natureza jurídica de sociedade simples.

19 A constituição das cooperativas no Brasil está em geral permeada pela concepção da $\mathrm{ACl} / \mathrm{OCB}$ que defendem aquilo que denominam como 'doutrina cooperativista'. No entanto, a história das cooperativas demonstra, que as cooperativas se formam a partir de diferentes iniciativas e a motivação e a organização dos grupos que as constituem levam a conformação de naturezas diferentes. A legislação cooperativista, por sua vez, não reconhece essa diferença, por representar o pensamento hegemônico e doutrinário do 'sistema único' do cooperativismo, que criou na década de 70 , no início do período da Ditadura Militar, a OCB e toda a forma de organização desse sistema e normatizou a constituição das cooperativas (Pontes, 2004, p. 115).

20 Art. 1.093. A sociedade cooperativa reger-se-á pelo disposto no presente Capítulo, ressalvada a legislação especial.

Art. 1.094. São características da sociedade cooperativa: [...]

21 Art. 982. Salvo as exceções expressas, considera-se empresária a sociedade que tem por objeto o exercício de atividade própria de empresário sujeito a registro (art. 967); e, simples, as demais.

Parágrafo único. Independentemente de seu objeto, considera-se empresária a sociedade por ações; e, simples, a cooperativa. 
Pelo inciso VII do artigo 1094 do CC, é previsto o princípio do retorno, o qual consiste na distribuição dos resultados aos cooperados das sobras (e também prejuízos) dos recursos recebidos pela sociedade em razão do exercício de suas atividades, na proporção das operações por eles efetuadas, podendo ser atribuído juro fixo ao capital realizado. A divisão de eventuais sobras não pode se confundir com a distribuição de lucros de uma sociedade empresarial, pois aquela divisão tem relação com as operações realizadas pelo associado e essa, eminentemente, com a participação do sócio no capital social. Em excelente evolução, o seu correspondente na lei especial, inciso VII do artigo $4^{\circ}$, foi parcialmente revogado, pois previa que a assembleia geral poderia decidir de outra forma sobre a distribuição dos resultados da cooperativa.

Com essa previsão anterior era possível que a assembleia geral decidisse, por exemplo, que o retorno das sobras seria proporcional ao capital investido, e não às atividades, o que poderia desvirtuar o próprio espírito cooperativista.

Nesse contexto, o fenômeno cooperativo implanta-se como o reconhecimento das formações sociais. No entanto, o mesmo fenômeno, considerado na sua totalidade, é adquirido ao assunto de outra disciplina constitucional contendo uma reserva de lei. À luz disso, é útil chamar a atenção para características específıcas e inseparáveis do fenômeno cooperativo, a saber:

1. A Cooperação como um exercício coletivo de negócios em forma mútua e, portanto, como uma afırmação da socialização da produção e do poder empreendedor;

2. A mutualidade, a essência do que é feito também consiste no modo democrático de gestão da sociedade;

3. A ausência de propósito de especulação privada, que diz respeito a entidade cooperativa, que não pode, portanto, agir apenas em razão do objetivo de alcançar rentabilidade;

4. A função social da cooperação (Bagnoli, 2011).

A referência à função social, para além do debate complexo e literário, parece oferecer um reconhecimento a montante, de natureza estrutural da espécie jurídico-econômica cooperativa, adequado para a realização dos objetivos contidos na sociedade em si. A iniciativa privada e a propriedade privada não só podem ser realizadas em conflito com a utilidade social, mas, acima de tudo, devem ser abordadas com direito comum, isto é, o desempenho de um papel de natureza social que de outra forma não seria necessariamente perseguido. 
Para a cooperação, no entanto, a Cl usa uma fórmula diferente: "A República reconhece a função social" e a CF: "A política agrícola será planejada e executada [...] levando em conta, especialmente o cooperativismo"22 (Constituição do Brasil, 1988).

A função social, em outras palavras, não é o objetivo do legislador, mas uma qualidade intrínseca do próprio fenômeno cooperativo. Nesse caso, portanto, há uma espécie de identificação pré-estabelecida, fisiológica, entre os objetivos prioritários e as características estruturais do fenômeno cooperativo.

É importante notar que os mesmos termos são expressos em outras constituições mais recentes do que a italiana. Em particular, é possível recordar a Constituição Portuguesa, que, no art. 61, reconhece a todos, incluindo os direitos econômicos, "[...] o direito à liberdade de estabelecimento de cooperativas, desde que observados os princípios cooperativos"'", e identifica, como um perfil organizatório da economia, no art. 82, aquele do setor cooperativo e social sempre em conformidade com os princípios de cooperação, atribuindo ao Estado a responsabilidade de estimular e apoiar a criação e as atividades das cooperativas, em conformidade com o art. 86.

Esse esclarecimento é importante, todavia, para estabelecer um alinhamento da legislação nos países da União Europeia, visando a formação de um direito cooperativo comunitário, por meio do Tratado da União Europeia (TUE).

Por óbvio, onde a função social é apresentada como uma característica intrínseca da própria atividade econômica, assim como ocorre com as cooperativas, o processo de harmonização comunitária deve ser facilitado. O projeto de lei da Sociedade Cooperativa Europeia, em 1989, e uma série de resoluções do Parlamento Europeu, sobre o apoio do movimento cooperativo em nível comunitário, foram as premissas iniciais que ganharam nível continental (as quais, no entanto, não resultaram em medidas concretas).

Nesse ponto do discurso, não parece supérfluo notar que a perspectiva de reconhecimento da função social da cooperação chama a atenção do intérprete para uma dimensão de valor essencial para entender a extensão das pressões do processo de unificação europeia.

$\mathrm{Na}$ conclusão dessas considerações gerais sobre a descrição do quadro constitucional do fenômeno cooperativo, deve-se recordar que profundas reflexões merecem não apenas poucas citações legislativas. Uma investigação constitucional sobre o fenômeno cooperativo consiste em constatar, ainda, como uma constituição

22 Art. 187. A política agrícola será planejada e executada, na forma da lei, com a participação efetiva de produção, envolvendo produtores e trabalhadores rurais, bem como dos setores de comercialização, de armazenamento e de transportes, levando em conta, especialmente:

VI - o cooperativismo. 
econômica, não sendo estranho para o projeto de sociedade e do Estado contidas nos princípios fundamentais das Constituições por ora analisadas (Bagnoli, 2011).

A cooperação, por seu turno, conforme visto, passa a ter valor fundamental para as Constituições brasileira e italiana, seguindo uma linha de outros países do mundo, mas terá seu ápice de atuação e de ingerência manifestamente na ordem econômica. A dignidade da pessoa humana, por seu turno, permanece, por fim, como um valor universal, como o centro das opções para a regulamentação das relações sociais, políticas e econômicas.

\section{Considerações Finais}

Cooperar é trabalhar de forma sincronizada em busca do mesmo objetivo. Sua prática educa, desenvolvendo nas pessoas um senso participativo, humano e solidário. Isso porque os estudos demonstraram entregar à cooperação papel de destaque nas relações humanas. Marx já dizia que a "cooperação traz ao trabalho um novo potencial produtivo, pois não se trata aqui da elevação da força produtiva individual através da cooperação, mas da criação de uma força" (1988, p. 217).

Com base no que se observou na análise do desenrolar histórico da cooperação e do movimento cooperativo no mundo, suas vertentes e justificativas para a existência das sociedades cooperativas tais como prenunciavam desde suas origens, é correto afırmar que a vida social é, de fato, toda permeada pela cooperação, uma vez que as pessoas se organizam em grupos para se adaptar ao ambiente e atender às suas necessidades. Na mesma linha de raciocínio, afirma-se que a sociedade seria impossível sem um mínimo de esforço cooperativo, principalmente para mantê-la. Da mesma forma ocorre com a economia.

Algumas vezes, a cooperação surge onde menos se espera, sendo tampouco necessária a amizade entre os envolvidos. Até mesmo pessoas em situações antagônicas podem cooperar. A operação cultural lançada pelos estudiosos do século XIX não foi, portanto, de pensar a cooperação como um grupo de sociedades em que se praticava a mutualidade em oposição ao motivo dominante e penetrante de lucro, mas de ler e interpretar a economia de mercado como um lugar de cooperação, mesmo diante de um conflito de interesses. Naquele momento, não havia mais certeza entre as mudanças sociais do futuro próximo de um crescimento progressivo do princípio e da prática da cooperação.

O fenômeno da cooperação assume, como visto, uma característica fundamental (ou, mais especificamente, um objetivo republicano fundamental), essencial e absoluta para a Constituição Federal, marcando, entretanto, além da necessária 
cooperação internacional entre os povos (art. 4 da CF), também a interferência direta na ordem econômica nacional.

Ademais, ainda há de se observar uma compatibilidade entre a cooperação e o fundamento da livre iniciativa, constante no art. 1, inciso IV da CF, demonstrando a existência de um Estado Democrático de Direito e uma ordem econômica e democrática. Outrossim, de nada serviria a busca por um desenvolvimento econômico, se não houver o atendimento ao social, com a efetiva proteção do desenvolvimento social e observância de preceitos constitucionais.

É crível perceber que, mesmo após diversas fases de altos e baixos, o movimento cooperativo mundial continua crescendo em larga escala e seu peso tem assumido cada vez mais posição como parte do tecido econômico e produtivo do mundo, apesar da crise econômica mais estrutural, em especial no Brasil e Itália (países com mais destaque neste estudo). Mas se antes se debatia sobre uma função social constitucional da cooperação, é absolutamente impossível a negação do seu papel frente à economia, ou seja, sua função econômica. Na realidade, em razão dessa função econômica (razão e fundamento de sua existência) é que a cooperação/ cooperativismo passou a ter reconhecimento e proteção constitucional.

O movimento da cooperação tem energia e formas para levar a essas novas estradas (mesmo que incertas ainda). O papel da investigação e da formação neste contexto é crucial. Qualquer investimento para melhorar o perfil do nosso conhecimento é um investimento para um futuro menos vulnerável. A cooperação mostra que há uma alternativa. É preciso retomar o pensamento e ação guiados pela igualdade e justiça social. Diante do capitalismo, e não buscando uma alternativa a ele, mas uma convivência pacífica, as formas apresentadas são de fato novas formas, não sendo possível precisar se definitivas ou não.

\section{Referências}

Axelrod, R. (1984). The evolution of the cooperation. New York: Library of Congress.

Bagnoli, L. (a cura di). (2011). La funzione sociale della cooperazione. Teorie, esperienze e prospettive. Carocci, Roma.

Benato, J. V. A. (1995). O ABC do Cooperativismo. 2.ed. São Paulo: ICA- OCESP.

Blanco, J. M. (1990). El retorno cooperativo. Zaragoza, España: Librería General. 
Boarati, V. (2006). Economia para o Direito. Barueri, SP: Manole.

Bonfante, G.; Ciuffoletti, Z.; Innocenti, M.; Sapelli, G. (1981). Il movimento cooperativo in Italia. Storia e problemi. Torino, Itália: Einaudi.

Bragadin, S. M. (Org.). (2005). Imprese e cooperative a confronto: regime differenziati e implicazioni sul mercato. Genova, Itália: Lindau.

Constituição da República Federativa do Brasil de 1988. (2003). Brasília: OAB.

Braudel, F. (2006). Civiltà materiale, economia e capitalismo. Le strutture del quotidiano (secoli XV-XVIII). Torino, Itália: Einaudi.

Bruni, L. (2006). Reciprocità. Dinamiche di cooperazione, economia e società civile. Milano, Itália: Bruno Mondadori.

Bulgarelli, W. (1998). As sociedades Cooperativas e sua disciplina jurídica. Rio de Janeiro: Renovar.

Cohen, J. (1989). Deliberation and democratic legitimacy, in The good polity. Oxford: A. Hamlin.

Coraggio, J L. (2011). Economía social y solidaria. El trabajo antes que el capital. Quito (Ecuador): Abya Yala.

CunHA, F. W. (1990). Direito Constitucional do Brasil. Rio de Janeiro: Renovar.

Di Marco, I.; De Pascale, R. (a cura di). (2013). Studio sulle Cooperative. Disciplina giuridica e case-study. Commissione Nazionale UNGDCEC.

Directiva 2003/72/CE. (2003). Estados Unidos.

Regulamento n 1435/2003. Estatuto da sociedade cooperativa europeia (SCE). 2003.

Filippini, M. (a cura di). (2014). Politica e discipline della cooperazione. Bologna, Itália. "Scienza \& Politica", introduzione e cura di, vol. 26, n. 50, pp. 1-93, 213-225.

Frau, M. (2010). La Coop non sei tu. La mutazione genética dele coop: dal solidarismo alle scalate bancarie. Firenze, Itália: Riuniti.

Costituzione della repubblica italiana. Codici e leggi d'italia. Luigi Franco , Virgilio Feroci e Santo Ferrari. Milano, Editore Ulrico Hoepli, 1994. 
O cooperativismo e a função social constitucional da cooperação nas constituições da Itália e do Brasil

Costituzione della repubblica italiana. Corte costituzionale. Disponível em http://www.cortecostituzionale.it/actionPronuncia.do. Acesso em: 14 de abril de 2020.

Krueger, G. (2002). A disciplina das cooperativas no Novo Código Civil- a ressalva da lei 5.764/71. In: Becho, R.. Problemas atuais do Direito Cooperativo. São Paulo: Dialética. p. 96-119.

Marx, K. (1988). O Capital: Crítica da economia política. Livro 1º, tomo 2, $3^{\text {a }}$ ed. São Paulo: Nova Cultural.

MAUAD, M. (2001). Cooperativas de trabalho. Sua relação com o direito do trabalho. 2.ed. Revista e atualizada. São Paulo: LTR.

Meinen, Ê.; Domingues, J. N.; Domingues, J. A. S. (2002). Aspectos Jurídicos do cooperativismo. Porto Alegre: Sagra Luzzatto.

NAmORADO, R. (2005). Cooperativismo -Um horizonte possível. In: GEDIEL, J. (org). Estudos de Direito Cooperativo e Cidadania. Curitiba: Programa de Pós Graduação em Direito da UFPR.

NAmoRAdo, R. (2013). O mistério do Cooperativismo. Coimbra: Almedina.

Nisbet, R. A. (1968). Cooperation. In: SILLS, David L. (ed) International Encyclopedia of the Social Sciences. VOL 3. New York: Macmillan and the Free Press.

Ramírez, B. (1989). Teoría y doctrina de la cooperación. Bogotá: Esacoop/ Fondo Nacional Universitario.

Salani, M. P. (org.). (2006). Lezione Cooperative: contributo ad una teoria dell'impresa cooperativa. Bologna, Itália: Società Editrice II Mulino.

Salani, M. P. (2008). Nueve Lezioni cooperative. Bologna, Itália: Società Editrice Il Mulino.

Sapelli, G. (2006). Coop: il futuro dell'impresa cooperativa. Torino, Itália: Giulio Einaudi.

Shaffer, J. (1999). Historical Dictionary of the Cooperative Movement. London: The Scarecrow.

Torres e Torres Lara, C. (1983). Cooperativismo -el modelo alternativo. Estudios sobre su ideología, instituciones y técnicas. Lima: Dirección de Proyección social.

Totomianz, V. (1938). Manual do Cooperativista. Porto: Imprensa Social. 
Vella, M. (2010). Oltre il motivo del profitto. Storia, economia, gestione e finanza delle imprese cooperative italiane. Siena, Itália: Maggioli.

Viola, F. (2004). Forme della cooperazione. Bologna, Itália: Il Mulino.

Zamagni, S. (2002). L'economia delle relazioni umane: verso il superamento dell'individualismo assiologico. In: SACCO, P. Luigi. (a cura di). Complessità relazionale e comportamento economico. Bologna, Itália: Il Mulino.

Zamagni, V. (2006). L'Impresa cooperativa italiana: dalla marginalità alla fioritura. Bologna, Itália: Unisiversità di Bologna. 